Article

\title{
In Vitro Drug Release, Permeability, and Structural Test of Ciprofloxacin-Loaded Nanofibers
}

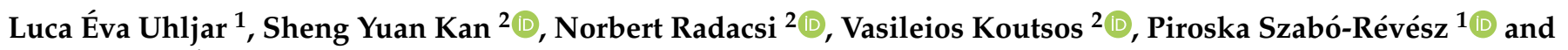 \\ Rita Ambrus 1,* \\ 1 Interdisciplinary Excellence Centre, Faculty of Pharmacy, \\ Institute of Pharmaceutical Technology and Regulatory Affairs, University of Szeged, Eötvös Street 6, H-6720 \\ Szeged, Hungary; uhljar.luca.eva@szte.hu (L.É.U.); ReveszPiroska@szte.hu (P.S.-R.) \\ 2 School of Engineering, Institute for Materials and Processes, The University of Edinburgh, King's Buildings, \\ Edinburgh EH9 3FB, UK; skyshengyuan@hotmail.com (S.Y.K.); n.radacsi@ed.ac.uk (N.R.); \\ vasileios.koutsos@ed.ac.uk (V.K.) \\ * Correspondence: ambrus.rita@szte.hu
}

Citation: Uhljar, L.É.; Kan, S.Y.;

Radacsi, N.; Koutsos, V.;

Szabó-Révész, P.; Ambrus, R. In Vitro

Drug Release, Permeability, and

Structural Test of

Ciprofloxacin-Loaded Nanofibers.

Pharmaceutics 2021, 13, 556.

https://doi.org/10.3390/

pharmaceutics13040556

Academic Editor: Marcel Popa

Received: 17 March 2021

Accepted: 12 April 2021

Published: 15 April 2021

Publisher's Note: MDPI stays neutral with regard to jurisdictional claims in published maps and institutional affiliations.

Copyright: (C) 2021 by the authors. Licensee MDPI, Basel, Switzerland. This article is an open access article distributed under the terms and conditions of the Creative Commons Attribution (CC BY) license (https:/ / creativecommons.org/licenses/by/ $4.0 /)$.

\begin{abstract}
Nanofibers of the poorly water-soluble antibiotic ciprofloxacin (CIP) were fabricated in the form of an amorphous solid dispersion by using poly(vinyl pyrrolidone) as a polymer matrix, by the low-cost electrospinning method. The solubility of the nanofibers as well as their in vitro diffusion were remarkably higher than those of the CIP powder or the physical mixture of the two components. The fiber size and morphology were optimized, and it was found that the addition of the CIP to the electrospinning solution decreased the nanofiber diameter, leading to an increased specific surface area. Structural characterization confirmed the interactions between the drug and the polymer and the amorphous state of CIP inside the nanofibers. Since the solubility of CIP is pH-dependent, the in vitro solubility and dissolution studies were executed at different $\mathrm{pH}$ levels. The nanofiber sample with the finest morphology demonstrated a significant increase in solubility both in water and pH 7.4 buffer. Single medium and two-stage biorelevant dissolution studies were performed, and the release mechanism was described by mathematical models. Besides, in vitro diffusion from $\mathrm{pH} 6.8$ to $\mathrm{pH} 7.4$ notably increased when compared with the pure drug and physical mixture. Ciprofloxacin-loaded poly(vinyl pyrrolidone) (PVP) nanofibers can be considered as fast-dissolving formulations with improved physicochemical properties.
\end{abstract}

Keywords: amorphous solid dispersion; ciprofloxacin; electrospinning; nanofibers; poorly watersoluble drug; povidone

\section{Introduction}

Nowadays, one of the main challenges in pharmaceutical technology is dealing with poorly water-soluble drugs. The number of Biopharmaceutics Classification System (BCS) Class II and Class IV drugs is estimated to make up $~ 40 \%$ of currently marketed drugs and $\sim 90 \%$ of compounds currently under development [1-3]. One of the BCS Class II/IV drugs is ciprofloxacin (CIP), which is a worldwide-used, broad-spectrum, second-generation fluoroquinolone antibiotic. Fluoroquinolones inhibit DNA replication in bacteria because their mechanism of action is the inhibition of bacterial DNA gyrase and topoisomerase IV. The lack of cross-resistance between fluoroquinolones and other classes of antibiotics makes this antibiotic family important. CIP and its derivatives can effectively treat antibioticresistant infections (e.g., nosocomial pneumonia), so they are usually reserved as "drugs of last resort" [4]. Since CIP is active against many Gram-negative and Gram-positive bacteria, it is directed to treat several bacterial infections. CIP is indicated for a broad spectrum of diseases, from bacterial conjunctivitis through bone and joint infections to complicated urinary tract infections. Accordingly, the available dosage forms on the market are ophthalmic and otic solutions, film-coated tablets, oral suspensions, and solutions 
for infusions. Thus, various routes for drug administration, both local and systemic, are applied. Despite common use, CIP has only $56-77 \%$ bioavailability [4]. The solubility of the drug is $\mathrm{pH}$-dependent, as CIP is highly soluble below $\mathrm{pH} 5$ and above $\mathrm{pH} 10$ but almost insoluble around neutral $\mathrm{pH}$ level [5]. According to the BCS, CIP belongs to Class $\mathrm{IV}$, with low water solubility $\left(0.067 \mathrm{mg} / \mathrm{mL}\right.$ at $25^{\circ} \mathrm{C}, \mathrm{pH} 7.5$; [6] $)$ and poor permeability [4].

In most cases, nanocarrier-based drug delivery systems can offer a solution to the low solubility problem of a drug. Nanostructures are innovative formulations with nanometerscale in at least one dimension and a large surface-area-to-volume ratio. The latter ensures that a large amount of the drug can come into contact with the surrounding medium. In this way, the dissolution rate and even solubility can increase [7-9]. Furthermore, numerous drug delivery systems contain the active pharmaceutical ingredient (API) in an amorphous state and therefore cause increased solubility of the drug [10,11]. With the increase of solubility and dissolution rate, the bioavailability of the API increases [12-14]. Currently, intensive research is underway to formulate CIP into different nanocarriers to treat several diseases. Some examples are collected in Table 1.

Table 1. Ciprofloxacin-loaded nanocarriers under investigation with the aimed indication.

\begin{tabular}{|c|c|c|c|c|}
\hline $\begin{array}{c}\text { Type of } \\
\text { Nanocarrier }\end{array}$ & $\begin{array}{l}\text { Excipients } \\
\text { Applied in } \\
\text { Nanocarrier }\end{array}$ & $\begin{array}{c}\text { Aimed } \\
\text { Indications }\end{array}$ & Targeted Organs & References \\
\hline $\begin{array}{c}\text { Polymeric } \\
\text { nanoparticles (NP) } \\
\text { in nanofibers (NF) }\end{array}$ & $\begin{array}{c}\text { PLGA and } \\
\text { PCL-NP } \\
\text { PEOT } / \mathrm{PBT}-\mathrm{NF}\end{array}$ & tissue engineering & middle ear & [15] \\
\hline $\begin{array}{c}\text { Nanoparticles and } \\
\text { coated } \\
\text { nanoparticles }\end{array}$ & $\begin{array}{c}\text { PLGA and } \\
\text { chitosan (coat) }\end{array}$ & root canal infection & tooth & [16] \\
\hline $\begin{array}{c}\text { Composite } \\
\text { nanoparticles }\end{array}$ & $\begin{array}{l}\text { synthetic nano-HA } \\
\text { and sodium } \\
\text { alginate }\end{array}$ & tissue engineering & bone & [17] \\
\hline Microspheres & PLGA & $\begin{array}{l}\text { osteomyelitis, } \\
\text { orthopedic } \\
\text { infections }\end{array}$ & bone & [18] \\
\hline Microparticles & $\begin{array}{c}\text { calcium carbonate, } \\
\text { sodium } \\
\text { hyaluronate }\end{array}$ & lung infections & lungs & [19] \\
\hline $\begin{array}{l}\text { Nanocrystals } \\
\text { inside liposomes }\end{array}$ & HSPC, cholesterol & lung infections & lungs & [20] \\
\hline $\begin{array}{l}\text { Amorphous } \\
\text { nanoparticle } \\
\text { complex }\end{array}$ & dextran sulfate & $\begin{array}{c}\text { non-cystic fibrosis } \\
\text { bronchiectasis }\end{array}$ & lungs & [21] \\
\hline $\begin{array}{c}\text { Lipid-core } \\
\text { nanocapsules }\end{array}$ & $\begin{array}{l}\text { PCL, sorbitan } \\
\text { monostearate, } \\
\text { oleic acid, } \\
\text { polysorbate } 80\end{array}$ & cystic fibrosis & lungs & [22] \\
\hline Nanofibers & PVP & wound infections & skin & [23] \\
\hline Nanofibers & $\begin{array}{l}\text { PVA, chitosan, } \\
\text { graphene oxide }\end{array}$ & wound infections & skin & [24] \\
\hline
\end{tabular}

Abbreviations: HA-hydroxyapatite; HSPC—hydrogenated soy phosphatidylcholine; PCL-poly( $\varepsilon$-caprolactone) PEOT/PBT_Poly(ethylene oxide terephthalate)/poly(butylene terephthalate) copolymer; PLGA-poly(D,Llactide-co-glycolide); PVA-poly(vinyl alcohol); PVP-poly(vinyl pyrrolidone).

Polymeric nanofibers are considered solid dispersions with a large specific surface area that can stabilize drugs in their amorphous state. Thus, polymer-based nanofibers provide an attractive approach for the development of dosage forms due to the enhanced solubility and dissolution rate $[25,26]$. Nanofibers have a variety of uses currently under investigation in different fields of science. In pharmaceutical and medical fields, at least four applications have to be mentioned: wound dressings, filtration, drug delivery systems, and tissue engineering scaffolds [27-31]. Electrospinning is an effective and inexpensive method for the fabrication of polymeric nanofibers; hence, it is the most widely used technique for nanofiber production in the industry. During the electrospinning procedure, which is generated by a high voltage power supply, the ejection and travel of the polymer-drug 
fluid jet are induced by the large potential difference between a needle and a collector [32]. As the jet travels towards the collector, the solvent evaporates, and the jet solidifies into nano-sized fibers. It is possible to control the mean fiber diameter and morphology by changing the polymer-drug solution, the applied voltage, the needle-collector distance, the flow rate, the collector speed, or the environmental temperature and humidity $[33,34]$.

Poly(vinyl pyrrolidone) (PVP) is a water-soluble and biocompatible polymer, which is commonly used as a pharmaceutical excipient and food additive [35]. PVP is also widely used as a carrier polymer that enables electrospinning [23,36-45].

Ciprofloxacin-loaded PVP nanofibers as potential wound dressings have been recently investigated [23,41,44]. However, to the best of our knowledge, the development of a potential per os formulation has not been published yet.

In this article, the preformulation studies of PVP-based nanofiber mats loaded with CIP for per os administration are investigated. The aim of the present study was to increase the water solubility and diffusion of the API and study the in vitro drug release and its kinetics. Additionally, the study aimed to investigate the effect of the polymerdrug solution and the flow rate on the fiber diameter and morphology. Special attention was paid to structural characterization, drug entrapment efficiency, solubility, in vitro dissolution, and in vitro diffusion of the CIP-loaded nanofibrous samples when producing immediate-release nanofibrous formulation, and therefore achieving effective antibiotic therapy.

\section{Materials and Methods}

\subsection{Materials}

Ciprofloxacin base (CIP; $\mathrm{Mw}=331.35$; purity $>98 \%$ ) was gifted by Teva Pharmaceutical Works Ltd. (Debrecen, Hungary). Polyvinylpyrrolidone (PVP) (Mw $=1,300,000)$ was obtained from Alfa Aesar (Lancashire, United Kingdom). Ethanol (99.99\% purity) and chloroform ( $99.8 \%$ purity) were purchased from Fisher Scientific (Loughborough, United Kingdom).

Phosphate buffer solutions (PBS, pH 7.4 and 6.8) were prepared in-house as follows. To prepare $1 \mathrm{~L}$ of the $\mathrm{pH}$ 7.4 PBS, $1.44 \mathrm{~g}$ disodium phosphate dihydrate $\left(\mathrm{Na}_{2} \mathrm{HPO}_{4} \times 2\right.$ $\left.\mathrm{H}_{2} \mathrm{O}\right), 0.12 \mathrm{~g}$ potassium dihydrogen phosphate $\left(\mathrm{KH}_{2} \mathrm{PO}_{4}\right), 8.00 \mathrm{~g}$ sodium chloride $(\mathrm{NaCl})$, and $0.20 \mathrm{~g}$ potassium chloride $(\mathrm{KCl})$ were dissolved in approximately $0.9 \mathrm{~L}$ of distilled water. Then the $\mathrm{pH}$ was adjusted to 7.4 using aqueous solutions of $\mathrm{NaOH}$, bringing the buffer up to a volume of $1 \mathrm{~L}$. For the preparation of $1 \mathrm{~L}$ of the $\mathrm{pH} 6.8 \mathrm{PBS}, 6.8 \mathrm{~g} \mathrm{KH}_{2} \mathrm{PO}_{4}$ was dissolved in $900 \mathrm{~mL}$ of distilled water before mixing $77.00 \mathrm{~mL}$ of aqueous solutions of $\mathrm{NaOH}(0.2 \mathrm{M})$. The $\mathrm{pH}$ was adjusted to 6.8 using the $\mathrm{NaOH}$ solution. All used chemicals were purchased from Sigma-Aldrich (Budapest, Hungary).

All other chemicals were analytical grade, and distilled water was used.

\subsection{Methods}

\subsubsection{Preparation of the Solutions for Electrospinning}

As the first step of the nanofiber preparation, the electrospinning solutions were prepared. PVP powder was dissolved in ethanol, whereas ciprofloxacin was dissolved in chloroform in a separate vessel. Constant stirring was applied to both at room temperature for $24 \mathrm{~h}$ to generate homogenous solutions using a magnetic stirrer at $700 \mathrm{rpm}$. The nominal concentration of the CIP solutions was $1 \mathrm{mg} / \mathrm{mL}$, while the polymer concentrations varied between $5-20 \% w / v$. The PVP and the drug solutions were mixed in 1:1, 1:2, 1:3 volume ratio, respectively, to yield the requested concentrations. The full details of the samples prepared are listed in Table 2. 
Table 2. The composition of each sample and their preparation procedures.

\begin{tabular}{cccc}
\hline Sample & $\begin{array}{c}\text { PVP Solution }(w / v \\
\text { \%) }\end{array}$ & PVP:CIP $(v / v)$ & Flow Rate (mL/h) \\
\hline NF1 & 5 & $1: 0$ & 2 \\
NF2 & 20 & $1: 3$ & 2 \\
NF3 & 15 & $1: 2$ & 2 \\
NF4 & 10 & $1: 1$ & 0.5 \\
NF5 & 10 & $1: 1$ & 1 \\
NF6 & 10 & $1: 1$ & 2 \\
NF7 & 10 & $1: 1$ & 3 \\
NF8 & 10 & $1: 1$ & 4 \\
\hline
\end{tabular}

\subsubsection{Electrospinning Procedure}

The prepared solutions were filled in $2 \mathrm{~mL}$ syringes fitted with stainless steel $20 \mathrm{G}$ needles. The electrospinning process was carried out using a commercially available electrospinning device (IME Medical Electrospinning, Waalre, The Netherlands; Figure 1). The applied potential difference was $24 \mathrm{kV}$, and the needle-collector distance was maintained at $10 \mathrm{~cm}$. Different flow rates $(0.5,1,2,3$, and $4 \mathrm{~mL} / \mathrm{h})$ were provided by a syringe pump (Table 2$)$. All the experiments were performed at ambient conditions $\left(23{ }^{\circ} \mathrm{C}\right.$ temperature and $36-42 \%$ relative humidity). Additionally, a control sample containing no CIP was prepared using the same conditions as were used for the other samples (a constant $2 \mathrm{~mL} / \mathrm{h}$ pump flow rate was used for the pure PVP sample).

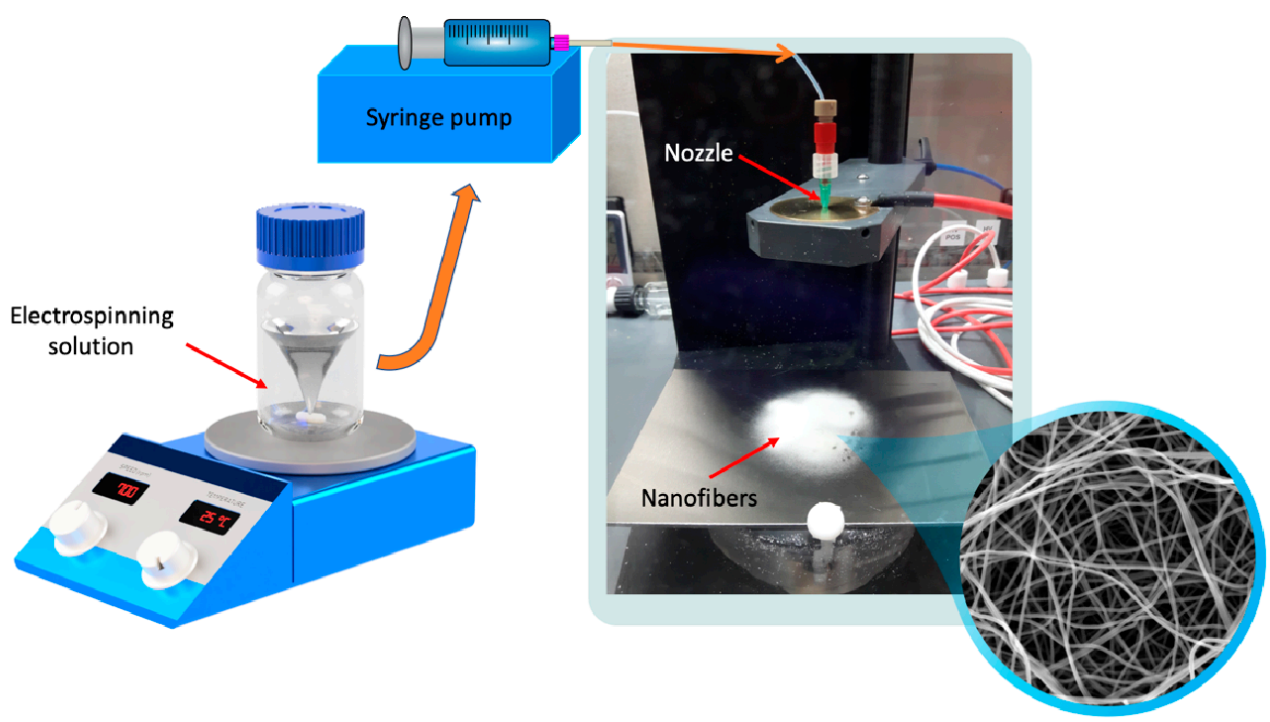

Figure 1. Preparation of ciprofloxacin-loaded nanofibers.

\subsubsection{Preparation of the Physical Mixture}

For the structural characterization and in vitro studies, physical mixtures were used as reference samples, prepared by a shaker mixer (Turbula System Schatz; Willy A. Bachofen AG Maschinenfabrik, Basel, Switzerland). PVP and CIP were homogenized under controlled conditions (50 rpm, $10 \mathrm{~min}$ ) in the same weight ratio as most nanofibrous samples.

\subsubsection{Size and Morphological Measurements}

The morphology of the electrospun nanofibers was observed by scanning electron microscopy (SEM; Hitachi S4700, Hitachi Scientific Ltd., Tokyo, Japan) at $10 \mathrm{kV}$. Specimens of the fiber mats $(0.4 \times 0.3 \mathrm{~cm})$ were cut and coated with approximately $10 \mathrm{~nm}$ thin film of gold-palladium using a sputter coater (Bio-Rad SC 502, VG Microtech, Uckfield, UK) 
before the SEM imaging was performed. One hundred fibers from each formulation were randomly selected to carry out the fiber diameter measurement (ImageJ 1.44p software; Bethesda, MD, USA).

\subsubsection{Structural Characterization}

CIP, physical mixture, and CIP-loaded nanofibers were characterized by X-ray powder diffraction (XRPD; D8 Advance, Bruker AXS GmbH, Karlsruhe, Germany). The samples were measured with $\mathrm{Cu} K \lambda_{\mathrm{I}}$ radiation $(40 \mathrm{kV} / 40 \mathrm{~mA}, \lambda=1.5406 \AA)$ in between diffraction angle $3-40^{\circ}$ for their structural properties.

Differential scanning calorimeter (DSC; Mettler Toledo DSC821e; Mettler Inc., Schwerzenbach, Switzerland) was applied to evaluate the thermal behavior of the samples using $25-300{ }^{\circ} \mathrm{C}$ temperature range at a heating rate of $5{ }^{\circ} \mathrm{C} \mathrm{min}^{-1}$.

Fourier transform infrared spectroscopy (FTIR; Thermo Nicolet AVATAR 330, Madison, WI, USA) was performed after discs of a $\mathrm{KBr}$ and nanofibers had been made by a compression molding technique. The discs were scanned 128 times over the range $4000-400 \mathrm{~cm}^{-1}$ and with a resolution of $4 \mathrm{~cm}^{-1}$.

\subsubsection{Drug Loading and Drug Entrapment Efficiency}

The drug loading and the amount of CIP entrapped in the optimized nanofibrous mat was quantified by UV spectrophotometry (ABL\&E-Jasco UV/VIS Spectrophotometer V-730, Budapest, Hungary). A known mass of NF6 sample (about $160 \mathrm{mg}$ ) was dissolved in $50 \mathrm{~mL}$ of $0.1 \mathrm{M}$ hydrochloric acid solution. The amount of CIP in the solution was calculated by UV spectroscopy analysis at a $\lambda_{\max }$ of $277 \mathrm{~nm}$.

The amount of the loaded CIP of the NF6 formulation was calculated by comparing the released mass of CIP ( $\left.\mathrm{w}_{U V}\right)$ with the mass of the dissolved nanofiber mat $\left(\mathrm{w}_{U V}\right)$. The drug loading (DL\%) was calculated by the following Equation (1).

$$
\operatorname{DL}(\%)=\left(\mathrm{w}_{U V} / \mathrm{w}_{M A T}\right) \times 100 .
$$

The drug entrapment efficiency of the nanofiber (EE) was calculated by the following Equation (2).

$$
\mathrm{EE}(\%)=\left(\mathrm{w}_{U V} / \mathrm{w}_{E S}\right) \times 100,
$$

where $\mathrm{w}_{U V}$ is the calculated mass of CIP released from the nanofibers, and $\mathrm{w}_{E S}$ is the mass of CIP dissolved before the electrospinning procedure.

Each experiment was performed in four parallel measurements, and the average values and standard deviations are reported.

\subsubsection{Solubility Tests}

Solubility tests were carried out both in distilled water and PBS (pH 7.4) as CIP is a poorly water-soluble drug and has a U-shaped $\mathrm{pH}$-dependent solubility with a minimum around $\mathrm{pH}$ 7.4. The first step was to place the pure drug, the physical mixture, and the drug-loaded nanofibrous samples in $3 \mathrm{~mL}$ of distilled water ( $\mathrm{pH}$ 6.3) or PBS (pH 7.4), which were then stirred for $24 \mathrm{~h}$ at room temperature with a magnetic bar. The samples were then filtered $(0.22 \mathrm{~mm}$, FilterBio PES Syringe Filter; Labex Ltd., Budapest, Hungary), suitably diluted, and measured by UV spectrophotometry (ABL\&E-Jasco UV/VIS Spectrophotometer V-730, Budapest, Hungary) at $275 \mathrm{~nm}$ and $271 \mathrm{~nm}$ in the case of water and PBS, respectively. The solubility tests of each sample were performed in triplicates, and the average values with the standard deviations are reported.

Additionally, the solubility of the CIP was measured with the same methodology in Fasted State Simulating Gastric Fluid (FaSSGF; Biorelevant.com accessed on 6 April 2021, London, UK) and Fasted State Simulating Intestinal Fluid (FaSSIF; Biorelevant.com accessed on 6 April 2021, London, UK) to get data for the in vitro two-stage drug release study. For the UV spectroscopy, $277 \mathrm{~nm}$ and $272 \mathrm{~nm}$ in the case of the FaSSGF and FaSSIF 
media were set as the wavelength of light, respectively. The results of the measurements are reported in Section 3.5.

\subsubsection{In Vitro Drug Release Studies}

Two types of in vitro drug release studies were executed to get a complete picture of the CIP release. Firstly, single medium dissolution ( $\mathrm{pH} 7.4 \mathrm{PBS}$ ) with a modified paddle method (Hanson Research SR8-Plus Dissolution Test Station, Chatsworth, CA, USA) was used to measure the drug release from NF6 nanofibers (containing $25 \mathrm{mg}$ CIP) compared with its corresponding physical mixture, and also with $25 \mathrm{mg}$ raw CIP powder. The release studies were carried out in $100 \mathrm{~mL}$ of the PBS medium at $37^{\circ} \mathrm{C}$. The paddle was rotated at $100 \mathrm{rpm}$. Then, $5 \mathrm{~mL}$ samples were taken manually from the buffer solution after 5, 10, 15, 30,60 , and $90 \mathrm{~min}$. After sampling, the volume was replaced with fresh PBS. The amount of drug present in the aliquots was determined with UV-Vis spectrophotometry (ABL\&EJasco UV/VIS Spectrophotometer V-730, Budapest, Hungary) at a $\lambda_{\max }$ of $275 \mathrm{~nm}$. The cumulative CIP release $(\sim 25 \mathrm{mg}=100 \%)$ was calculated using the calibration curve of CIP in pH 7.4 PBS. Each experiment was performed in triplicate, and the average values and standard deviations are reported.

Besides, to mimic the in vivo conditions better, a two-stage release test as a biorelevant gastrointestinal transfer protocol was also studied by the Hanson dissolution tester mentioned above. A portion of $25 \mathrm{mg}$ CIP powder was compared with a 100-fold larger mass of NF6 electrospun sample as the nanofibers were containing $1 \mathrm{w} / \mathrm{w} \%$ CIP. The samples were first added to $25 \mathrm{~mL}$ of FaSSGF, and $2 \mathrm{~mL}$ aliquots were taken at the time points: 1 , $3,5,10,15$, and $30 \mathrm{~min}$. Right after the last sampling, $25 \mathrm{~mL}$ of FaSSIF Concentrate, as a "bolus", was quickly added to the gastric medium. The FaSSIF Concentrate's surfactant concentration and buffer strength are doubled compared with those of regular FaSSIF. In this way, after the addition of $25 \mathrm{~mL}$ of FaSSIF Concentrate to $25 \mathrm{~mL}$ of FaSSGF, the final dissolution medium will be the regular FaSSIF. The methodology and the preparation of the FaSSIF Concentrate are reported by J. Mann et al. [46]. Next, $2 \mathrm{~mL}$ aliquots were taken $1,3,5,10,15,30$, and 60 min after the medium change. Each taken volume was replaced with fresh FaSSIF media. The dissolution vessels were thermostated at $37{ }^{\circ} \mathrm{C}$, and the paddle speed was set to $100 \mathrm{rpm}$ during the experiment. Similar to the first release study, the cumulative drug release $(\sim 25 \mathrm{mg}=100 \%)$ was calculated from the absorbance values measured by UV-Vis spectrophotometry at a $\lambda_{\max }$ of $277 \mathrm{~nm}$ and $272 \mathrm{~nm}$ in the case of the FaSSGF and FaSSIF media, respectively. Each experiment was performed in triplicate, and the average values and standard deviations are reported.

\subsubsection{Study of Drug-Release Kinetics and Mechanism}

The release kinetics of CIP from the electrospun nanofiber and physical mixture was compared with the dissolution kinetics of the CIP powder. Five different mathematical models (zero order, first order, Hixson-Crowell, Higuchi, and Korsmeyer-Peppas model) were fitted with the obtained cumulative drug release vs. time curves to describe the kinetics. To evaluate which model was followed, the value of the regression coefficient $\left(R^{2}\right)$ was determined and compared.

\subsubsection{In Vitro Diffusion Study}

For the estimation of the passive diffusion of CIP through biological membranes, the Side-Bi-Side $^{\mathrm{TM}}$ (Crown Glass, Somerville, NJ, USA) diffusion test was carried out. The cellulose ester membrane (pore diameter $=0.45 \mu \mathrm{m}$ ) was dipped in isopropyl myristate before use. The donor phase was pH 6.8 PBS, and the acceptor phase was pH 7.4 PBS; both were kept at $37{ }^{\circ} \mathrm{C}$ temperature. The diffused drug content was measured in real-time at $272 \mathrm{~nm}$ by AvaLight DH-S-BAL spectrophotometer (AVANTES, Apeldoorn, The Netherlands) connected to an AvaSpec-2048L transmission immersion probe (AVANTES, Apeldoorn, The Netherlands). The optical path length was $1 \mathrm{~cm}$. The diffusion tests of each sample 
were performed in triplicates, and the average values with the standard deviations are reported.

The flux, J, was calculated from the linear part of the graph using the following Equation (3):

$$
J=\partial m /(A \partial t),
$$

where $m$ is the cumulative amount of API transported in $t$ time, and $A$ is the surface area of the membrane $\left(0.875 \mathrm{~cm}^{2}\right)$. The permeability coefficient $\left(K_{p}\right)$ was determined by normalizing the flux to the donor concentration $\left(C_{d}\right)$, according to the Equation (4):

$$
K_{p}=J / C_{d}
$$

\subsubsection{Statistical Analysis}

The significance levels of the differences between the measured fiber diameters of the samples produced under different parameters were examined by one-way analysis of variance (ANOVA) with post hoc Tukey HSD test. All the experimental results of solubility and single medium dissolution tests are expressed as mean \pm standard deviation and statistically compared by a two-sample $t$-test. The experimental results with $p$ values $<0.05$, $<0.01$, and $<0.001$ were assumed to be statistically significant.

\section{Results and Discussion}

\subsection{Optimization of the Electrospinning Parameters}

Reviewing the works focusing on the electrospinning of drug-loaded PVP nanofibers, the solution flow rate was found to range between 0.2 and $2 \mathrm{~mL} / \mathrm{h}$ [23,36-45]. The average fiber diameter of the different formulations was largely varying. One of the aims of this research was to investigate the effect of flow rate on the diameter of PVP nanofibers, keeping the other preparation parameters constant. Additionally, nanofibers with different PVP:CIP volume ratios were prepared and studied. SEM was used to visualize the nanofibers, and then their morphology was observed, and the average fiber diameter was measured. The narrowest nanofiber formulation with the finest morphology was targeted during the optimization.

The morphology of drug-free and various drug-loaded nanofibers are represented in Table 3 and Figure 2. Continuous, smooth-surfaced nanofibers were successfully prepared from all the solutions studied except for sample NF3. PVP:CIP 1:2 volume ratio eventuated discontinuous, worm-like nanofibers with largely varying diameters (889 $\pm 265 \mathrm{~nm})$. The average diameter of the pure PVP fibers was $815 \pm 216 \mathrm{~nm}$. Considering the continuous fibers, the addition of the CIP decreased the fiber diameter. The decrease was significant except for sample NF2 (Table 4). This is expected to be related to the increase in the conductivity of the electrospinning solutions by adding the CIP [47]. Higher solution conductivity could facilitate the elongation of the jet and generate thinner fibers [48]. Additionally, the PVP nanofibers had some narrowing that slightly resembled the formation of beads, as shown in Figure 2. This was probably due to the low PVP concentration [49]. As the flow rate was increased, the average fiber diameter increased, which was expected from the literature [49]. However, the difference was not significant in every case (Table 4). Besides, the $3 \mathrm{~mL} / \mathrm{h}$ flow rate (NF7) caused incomplete solvent evaporation and merged fibers, while the sample produced by $4 \mathrm{~mL} / \mathrm{h}$ flow rate (NF8) showed some bead-like structures on top of the merged fibers (Figure 2). According to the results of this study, two formulations-namely, NF5 and NF6 - had the most optimal morphology and diameter distribution. Thus, the 1:1 ratio between the PVP and CIP was found optimal, similar to our previous study [50]. The higher flow rate is desirable for the preparation of samples because of the larger number of nanofibers produced during the same period of time. Since the applied flow rate of NF6 was 2 times higher than the flow rate of NF5, finally, NF6 was selected for further studies. 
Table 3. Fiber morphology and average diameter for different formulations.

\begin{tabular}{cccc}
\hline Sample & \multicolumn{2}{c}{ Fiber Morphology } & $\begin{array}{c}\text { Average Diameter } \\
\text { (nm) }\end{array}$ \\
\hline NF1 & continuous & smooth & $815 \pm 216$ \\
NF2 & continuous & smooth & $787 \pm 140$ \\
NF3 & discontinuous & worm-like & $889 \pm 265$ \\
NF4 & continuous & smooth & $542 \pm 103$ \\
NF5 & continuous & smooth & $601 \pm 87$ \\
NF6 & continuous & smooth & $645 \pm 82$ \\
NF7 & continuous & smooth & $663 \pm 79$ \\
NF8 & continuous & rough & $718 \pm 105$ \\
\hline
\end{tabular}

Table 4. $\mathrm{Q}$ statistic values of the different nanofibrous formulations as pairs of treatments in one-way ANOVA with post hoc Tukey HSD test. The significantly different ${ }^{* *} p<0.01$; $\left.{ }^{*} p<0.05\right)$ pairs of treatments are marked.

\begin{tabular}{ccccccccc}
\hline Sample & NF1 & NF2 & NF3 & NF4 & NF5 & NF6 & NF7 & NF8 \\
\hline NF1 & - & $1.77^{*}$ & $4.54^{*}$ & $15.47^{* *}$ & $12.54^{* *}$ & $9.91^{* *}$ & $7.88^{* *}$ & $4.31^{*}$ \\
NF2 & $1.77^{* *}$ & - & $6.45^{* *}$ & $14.24^{* *}$ & $11.21^{* *}$ & $8.51^{* *}$ & $6.58^{* *}$ & 3.12 \\
NF3 & $4.54^{*}$ & $6.45^{* *}$ & - & $19.67^{* *}$ & $16.88^{* *}$ & $14.21^{* *}$ & $11.69^{* *}$ & $7.58^{* *}$ \\
NF4 & $15.47^{* *}$ & $14.24^{* *}$ & $19.67^{* *}$ & - & 3.19 & $5.53^{* *}$ & $5.85^{* *}$ & $7.46^{* *}$ \\
NF5 & $12.54^{* *}$ & $11.21^{* *}$ & $16.88^{* *}$ & 3.19 & - & 2.43 & 3.07 & $5.05^{* *}$ \\
NF6 & $9.91^{* *}$ & $8.51^{* *}$ & $14.21^{* *}$ & $5.53^{* *}$ & 2.43 & - & 0.88 & 3.15 \\
NF7 & $7.88^{* *}$ & $6.58^{* *}$ & $11.69^{* *}$ & $5.85^{* *}$ & 3.07 & 0.88 & - & 2.23 \\
NF8 & $4.31^{*}$ & $3.12^{* *}$ & $7.58^{* *}$ & $7.46^{* *}$ & $5.05^{* *}$ & 3.15 & 2.23 & - \\
\hline
\end{tabular}

\subsection{Structural Characterization}

The change in the crystallinity of CIP was studied by XRPD and DSC (Figure 3A,B). The XRPD of the CIP powder showed high crystallinity, represented by several smaller and three longer sharp peaks at around 2-Theta $=14.5,20.9$, and $25.4^{\circ}$. The diffractogram of the physical mixture also had the same peaks along with a broad peak between $2-$ Theta $=7-15^{\circ}$. The broad peak that appeared in the diffractogram of PVP, physical mixture, and the half of nanofibrous samples prove the polymer's amorphous nature. The three characteristic peaks of the CIP were missing from the spectra of the nanofibrous samples, which indicates physicochemical interactions between the drug and the polymer matrix and the amorphous form of CIP created by the fast evaporation of the solvent during electrospinning. 

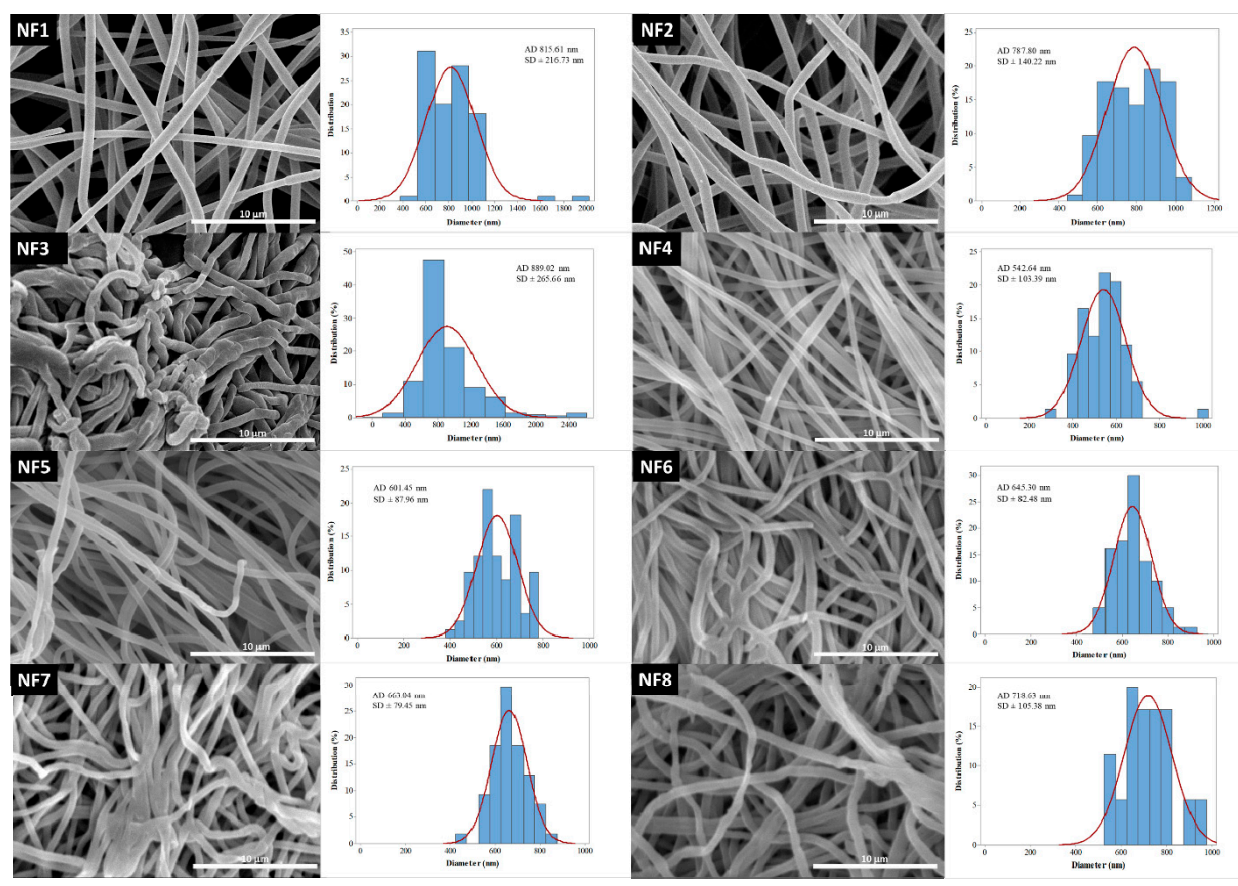

Figure 2. SEM images and diameter distributions of nanofibrous samples (5000× magnification).
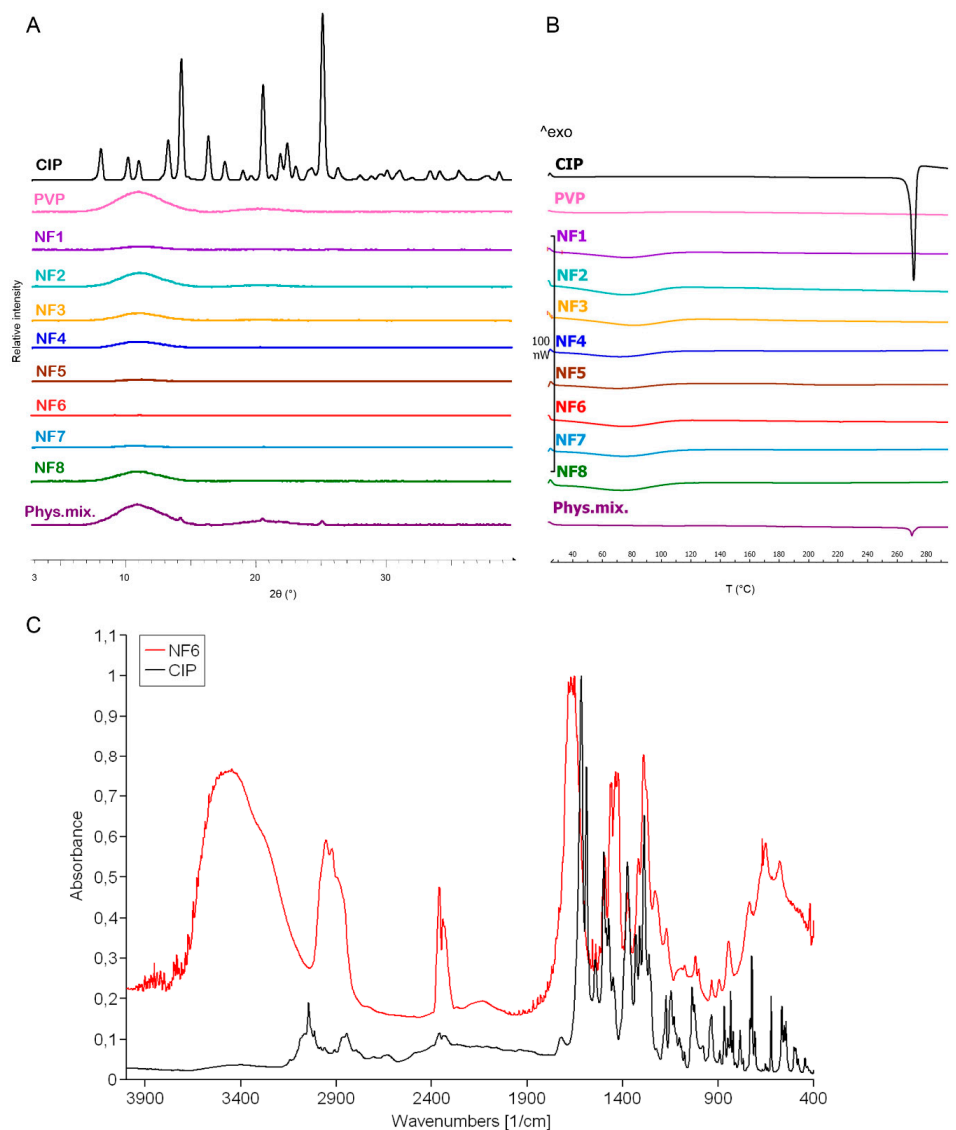

Figure 3. XRPD diffractogram (A) and DSC thermograms (B) of ciprofloxacin (CIP), PVP, physical mixture, and NF1-NF8 nanofibrous samples. All the electrospun samples are amorphous solid dispersions. FTIR spectra (C) of CIP and NF6 nanofibrous sample. The observed shifts and widenings confirm the successful incorporation of the CIP into the polymeric fibers. 
Figure 3B presents the DSC thermograms of CIP, PVP, physical mixture, and all the samples listed in Table 2. The melting point of the pure drug is well-defined by a large endothermic peak at $275{ }^{\circ} \mathrm{C}$, also appearing on the thermogram of the physical mixture. However, the flat PVP and NF1-NF8 thermograms suggest amorphous components. It can be concluded from both results that the drug was incorporated in amorphous form into the nanofibers.

Main drug-polymer interactions were observed by FTIR, and the spectra are given in Figure 3C. One prominent characteristic CIP peak at $1732 \mathrm{~cm}^{-1}(v C=O)$ shifted toward the higher wavenumbers and stretched due to the interaction with the hydroxyl groups of the PVP [51]. The wide band between 3050-3750 $\mathrm{cm}^{-1}(v \mathrm{C}-\mathrm{OH})$ was enlarged by the hydrogen bonding between the CIP and PVP in the nanofibers. Moreover, the bands between 3050-2750 $\mathrm{cm}^{-1}$ (alkene and aromatic $\left.v \mathrm{C}-\mathrm{H}\right)$, between $2380-2275 \mathrm{~cm}^{-1}(v \mathrm{C}$ $\mathrm{N})$, at $1500 \mathrm{~cm}^{-1}$ (quinolone), and at $1290 \mathrm{~cm}^{-1}$ ( $\left.\mathrm{vC}-\mathrm{O}\right)$ appeared wider in case of the nanofiber [52]. These shifts and widenings confirm the successful incorporation of the CIP into the polymeric fibers.

\subsection{Drug Loading and Drug Entrapment Efficiency}

Nanofibers, in general, exhibit very high entrapment efficiency because the electrospinning procedure can be considered as an in situ solidification of a polymer solution. Since both CIP and PVP are non-volatile in nature, high entrapment efficiency was expected under the consideration of complete miscibility.

Entrapment efficiency, as well as drug loading, was calculated by UV spectrophotometry. Solvent with low $\mathrm{pH}(0.1 \mathrm{M} \mathrm{HCl})$ was used to earn complete dissolution. The NF6 nanofibrous sample met our expectations with $92 \pm 8 \%$ entrapment efficiency. Furthermore, the theoretical drug loading of the NF6 formulation was $0.99 \%$, while the calculated drug loading was $0.92 \pm 0.08 \%$. These data are consistent with the high entrapment efficiency.

\subsection{Solubility Test}

The optimization study revealed that the sample NF6 had the most promising size and morphology for the solubility and dissolution studies. Solubility tests of the raw CIP powder, the physical mixture, and the drug-loaded nanofibrous samples were carried out in distilled water and PBS, as shown in Table 5. CIP has a pH-dependent, U-shaped solubility profile showing high solubility at $\mathrm{pH}<5$ and $\mathrm{pH}>10$ and poor solubility around neutral $\mathrm{pH}$ level as its isoelectric point is 7.42 [5]. Thus, distilled water and $\mathrm{pH} 7.4$ PBS were chosen as solvents to observe the effect of the polymer nanocarrier on the solubility. The $\mathrm{pH}$ was measured at the beginning and the end of the tests. The $\mathrm{pH}$ values of the solvents before adding the CIP were 6.3 and 7.4 in the case of the distilled water and PBS, respectively. During the $24 \mathrm{~h}$ solubility study, the $\mathrm{pH}$ of the CIP solution in water increased to 7.1 because CIP as a weak base slightly alkalized the solution. With the increase of the $\mathrm{pH}$ level, the solubility of the drug decreases, which reduces the dissolution of the remaining solid CIP in the system. The buffer capacity of the PBS was sufficient to prevent a notable $\mathrm{pH}$ shift.

Table 5. Solubility data of the samples in distilled water and phosphate buffer. The dissolution of the ciprofloxacin (CIP) shifted the $\mathrm{pH}$ from 6.3 to 7.1 in distilled water. The nanofiber NF6 has significantly higher $\left({ }^{* *} p<0.01 ;{ }^{*} p<0.05\right)$ solubility than the physical mixture and the raw CIP powder. Statistical analysis: Two-sample $t$-test.

\begin{tabular}{|c|c|c|}
\hline Sample & $\begin{array}{l}\text { Solubility }[\mathrm{mg} / \mathrm{mL}] \text { in Water } \\
\qquad(\mathrm{pH} 6.3 \rightarrow \mathrm{pH} 7.1)\end{array}$ & $\begin{array}{c}\text { Solubility }[\mathrm{mg} / \mathrm{mL}] \text { in PBS } \\
(\mathrm{pH} 7.4)\end{array}$ \\
\hline CIP & $0.071 \pm 0.001$ & $0.099 \pm 0.001$ \\
\hline Physical mixture & $0.182 \pm 0.035\rceil * * \mid * *$ & $0.123 \pm 0.0017$ \\
\hline Nanofiber (NF6) & $0.862 \pm 0.074]$ & ] \\
\hline
\end{tabular}


Studies with both solvents suggested that the incorporation of CIP into nanofibers caused a significant increase $(p<0.01$ in the case of water and $p<0.05$ in the case of PBS) in the drug solubility. In distilled water, the final CIP concentration showed a 12fold increase in the case of nanofibers compared with the raw CIP, while in the PBS, the nanofibers were approx. 6.4 times more soluble. Furthermore, the solubility of the drug in the physical mixture was not significantly higher in either solvent. Thus, it can be seen that only the presence of PVP could enhance solubility by increasing wettability. However, this enhancement was much lower than in the case of nanofibers, where solid molecular dispersion of CIP formed during the electrospinning procedure. Solid molecular dispersions can guarantee increased solubility by decreasing the particle size and improving wettability. This finding may be correlated with the characterization results because inside the nanofiber the CIP is in its amorphous form.

\subsection{In Vitro Drug Release}

The in vitro release profiles of electrospun nanofibers and raw CIP powder were investigated both in single medium dissolution and two-stage biorelevant release tests. On the one hand, pH 7.4 PBS was chosen as a medium, while in this pH level, CIP has a minimum solubility value, and the $\mathrm{pH}$ of the terminal ileum [53], as well as the blood, is around 7.4. The $\mathrm{pH}$-dependent solubility of a drug can cause incomplete dissolution or precipitation, which leads to suboptimal bioavailability. This might generate a problem with CIP because it occurs mostly at high administered doses [4]. On the other hand, any $\mathrm{pH}$ shift that occurs during the transfer from the stomach to the small intestine may affect the solubility and the bioavailability of CIP [54]. To investigate this effect, conditions similar to in vivo (biosimilar media, change in $\mathrm{pH}$ after $30 \mathrm{~min}$, body temperature) were used by a two-stage release study [46].

Figure 4 presents the cumulative drug release vs. time curves of CIP powder, physical mixture, and electrospun sample (NF6) measured in PBS (pH 7.4). In the case of the CIP powder, the dissolution was not complete within $90 \mathrm{~min}$, most probably due to the poor solubility of the drug at this $\mathrm{pH}$. Until $90 \mathrm{~min}$, only $41 \pm 3 \%$ of the drug was liberated. Similarly, the drug release from the physical mixture was $67 \pm 12 \%$ at the end of the measurement $(90 \mathrm{~min})$. However, NF6 showed a significantly higher dissolution rate than CIP powder $(p<0.001)$ at every measured point. Additionally, the nanofibrous sample demonstrated significantly higher drug release than the physical mixture $(p<0.05)$ in time points at 5 and $10 \mathrm{~min}$. Besides, while all the samples showed fast dissolution behavior, the release was the fastest from the nanofibers. The improved dissolution rate resulted in $94 \pm 6 \%$ dissolved CIP within only $5 \mathrm{~min}$. The distinct difference between the raw CIP and the nanofibers could be caused by the high surface-to-volume ratio, the high wettability, and the amorphous drug inside the nanofibers.

In addition, a two-stage biorelevant release study was executed to mimic the in vivo conditions since the solubility of CIP is sensitive to changes in $\mathrm{pH}$ of the gastrointestinal environment. The raw CIP powder and the NF6 nanofibrous sample were placed into $25 \mathrm{~mL}$ of FaSSGF medium, and the drug release was studied for $30 \mathrm{~min}$. From the raw $\mathrm{CIP}$, the release was fast and complete as the whole amount of the added powder was dissolved within $10 \mathrm{~min}$ (Figure 5). This was expected since Hansmann et al. published a similar result with Ciprobay ${ }^{\circledR} 500 \mathrm{mg}$ IR tablet [54], and the $24 \mathrm{~h}$ solubility test in FaSSGF (described in Section 2.2.7) showed $7.794 \pm 0.675 \mathrm{mg} / \mathrm{mL}$ average CIP concentration. However, in the case of the electrospun sample, the drug release was slower. It barely reached $90 \%$ until the last sampling of the FaSSGF medium. The difference could have been caused by the strong gelation of the high molecular weight PVP $(\mathrm{Mw}=1,300,000)$ in low $\mathrm{pH}$ levels forming a viscous matrix around the CIP, which could remarkably slow down its diffusion to the dissolution medium. 


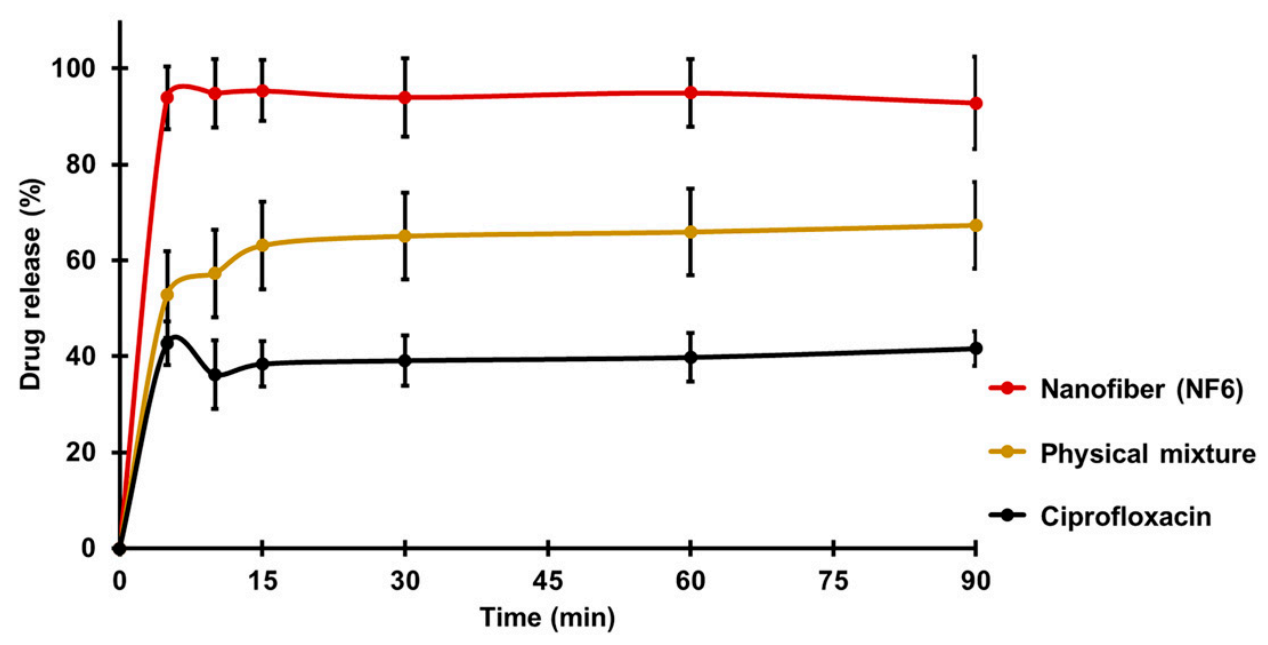

Figure 4. In vitro dissolution of ciprofloxacin (CIP) from NF6 nanofiber, physical mixture, and CIP powder in $\mathrm{pH} 7.4$ phosphate buffer solution. All measured NF6 values were significantly higher than the raw CIP values $(p<0.001)$, and the first two were significantly higher than the physical mixture values $(p<0.05)$. Statistical analysis: Two-sample $t$-test.

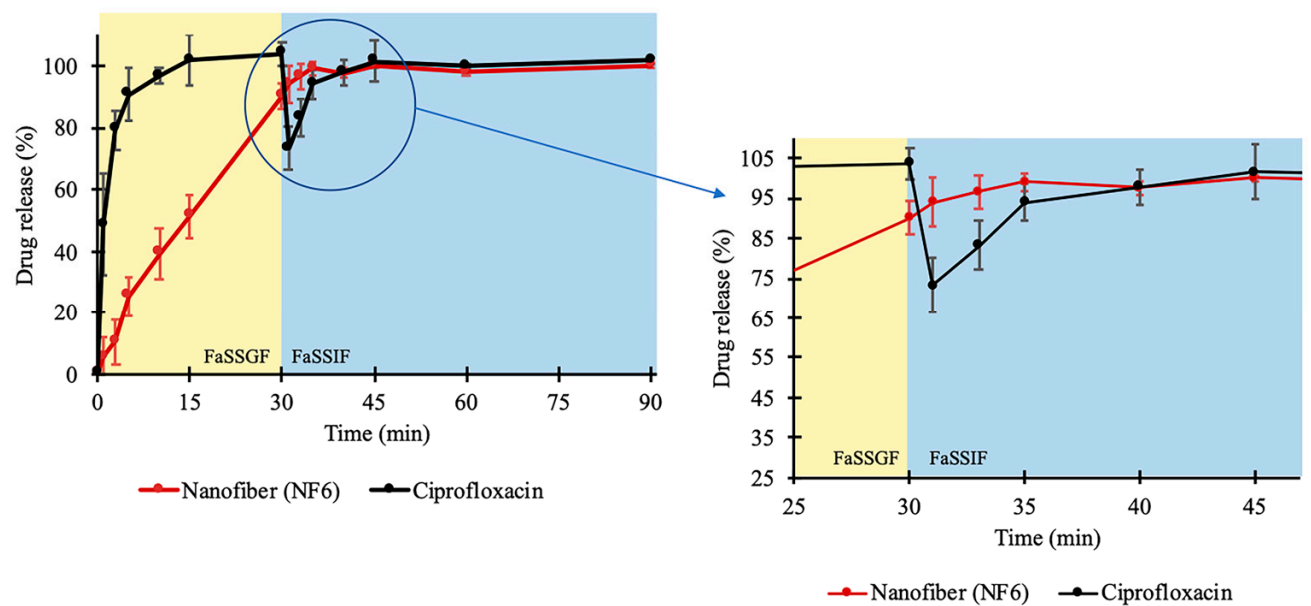

Figure 5. In vitro dissolution of ciprofloxacin (CIP) from NF6 nanofiber and CIP powder during the two-stage biorelevant release study. The dissolution medium (FaSSGF) simulated gastric condition until 30 min when the medium was turned into FaSSIF biorelevant fluid. The time range around the change of the medium (25-45 $\mathrm{min}$ ) is magnified for better visualization.

As the second phase of the two-stage study, at 30 min, FaSSIF Concentrate was added to the FaSSGF dissolution medium to create a 1:1 volume ratio mixture (FaSSIF medium). With this step, the emptying of the stomach into the small intestine is modeled easily [54,55]. Due to the change of $\mathrm{pH}$, the solubility of CIP decreased. As a result of the $24 \mathrm{~h}$ solubility test, $0.205 \pm 0.002 \mathrm{mg} / \mathrm{mL}$ drug concentration was detected in FaSSIF (described in Section 2.2.7). In the case of the raw CIP samples, this 38-fold decrease caused the precipitation of the pre-dissolved CIP, which was visible in the vessels. Additionally, a slope can be observed at the $30 \mathrm{~min}$ time point in Figure 5. Interestingly, the curve of the nanofibrous sample has no slope, while the dissolution of the drug continued even after the change of the medium. Controlled release without precipitation was observed in the case of the electrospun sample. From the time point at $40 \mathrm{~min}$, the two curves run together at around $100 \%$. The time range between 25 and 45 min is magnified in Figure 5. 


\subsection{Drug-Release Kinetics and Mechanism}

To describe the release kinetics from nanofibers, five different mathematical models are usually used-namely, zero order, first order, Hixson-Crowell model, Higuchi model, and Korsmeyer-Peppas model. The regression coefficient $\left(R^{2}\right)$ values of the different drug release models are listed in Table 6.

Table 6. Regression coefficient values of the different drug release models.

\begin{tabular}{cccccccc}
\hline $\begin{array}{c}\text { Release } \\
\text { Study }\end{array}$ & \multicolumn{2}{c}{ Single Medium (pH 7.4 PBS) } & \multicolumn{2}{c}{$\begin{array}{c}\text { Two-Stage Biorelevant } \\
\text { (FaSSGF) }\end{array}$} & \multicolumn{2}{c}{$\begin{array}{c}\text { Two-Stage Biorelevant } \\
\text { (FaSSIF) }\end{array}$} \\
Sample & CIP & $\begin{array}{c}\text { Physical } \\
\text { Mixture }\end{array}$ & $\begin{array}{c}\text { Nanofiber } \\
\text { (NF6) }\end{array}$ & CIP & $\begin{array}{c}\text { Nanofiber } \\
\text { (NF6) }\end{array}$ & CIP & $\begin{array}{c}\text { Nanofiber } \\
\text { (NF6) }\end{array}$ \\
\hline $\begin{array}{c}\text { Zero order } \\
\text { Fist order }\end{array}$ & 0.3270 & 0.2955 & 0.6122 & 0.5820 & 0.9810 & 0.2687 & 0.2344 \\
$\begin{array}{c}\text { Hixson- } \\
\text { Crowell }\end{array}$ & 0.3449 & 0.6565 & 0.9807 & 0.9085 & 0.9602 & 0.9276 & 0.9268 \\
$\begin{array}{c}\text { Higuchi } \\
\text { Korsmeyer- } \\
\text { Peppas }\end{array}$ & 0.8908 & 0.8540 & 0.6431 & 0.9204 & 0.9873 & 0.6452 & 0.5282 \\
\hline
\end{tabular}

In the case of the single medium (pH 7.4 PBS) dissolution study, the KorsmeyerPeppas model showed superiority over the other models studied for describing the release kinetic of the raw CIP, the physical mixture, and the NF6 electrospun sample. However, the Korsmeyer-Peppas model could not be fitted very well to the curves of CIP powder $\left(R^{2}=0.8967\right)$ and physical mixture $\left(R^{2}=0.8684\right)$, while the drug release of nanofibers was almost perfectly described by the model $\left(R^{2}=0.9993\right)$. This is reasonable since the Korsmeyer-Peppas model describes drug release from a polymeric system. It takes into account several mechanisms simultaneously, such as the diffusion of water into the polymer matrix, the swelling, and the dissolution of the polymer [52,56].

Furthermore, the Korsmeyer-Peppas model showed a high $R^{2}$ value both in FaSSGF $\left(R^{2}=0.9794\right)$ and FaSSIF $\left(R^{2}=0.9229\right)$, considering the release kinetics of the two-stage biorelevant dissolution study. However, in the case of the latter, the first order kinetics could be fitted to the curve even more precisely $\left(R^{2}=0.9268\right)$. First order was found to be the release kinetics of the raw CIP in FaSSIF medium as well, which means that the dissolution rate of CIP from the PVP matrix was dependent on the drug concentration. This can be explained by the change of $\mathrm{pH}$ caused by the change of the medium at $30 \mathrm{~min}$. The solution was supersaturated, and the higher $\mathrm{pH}$ caused the decrease of the solubility of the drug. Near to its solubility limit, the concentration of the CIP could affect the release kinetics.

In terms of the other medium, the release of the CIP powder followed the Higuchi model $\left(R^{2}=0.9502\right)$ while the highest $R^{2}$ values of the nanofibrous sample were related to zero order $\left(R^{2}=0.9810\right)$ and the Hixson-Crowell model $\left(R^{2}=0.9873\right)$. The difference in the course of the curves can also be seen in Figure 5. The Higuchi model describes drug release from different matrix systems that contain water-soluble drugs [52]. The FaSSGF is a good solvent of the CIP and without any polymer in the system, it could dissolve freely. On the other hand, the PVP formed a viscous hemisphere gel at the bottom of the vessel, causing the Hixson-Crowell model. This release model considers the dissolution of a tablet or polymer matrix but with the maintenance of their geometrical characteristics.

\subsection{In Vitro Diffusion Study}

An in vitro diffusion study was executed to compare the capacity of CIP from different samples (NF6 nanofiber, physical mixture, CIP powder) for crossing biological barriers, e.g., the small intestine cells (Figure 6). In the literature, it is suggested that the CIP is absorbed from the duodenum and the proximal jejunum [57]. Thus, during the in vitro diffusion study, $\mathrm{pH}$ 6.8 PBS was used for the donor phase. The acceptor phase (pH 7.4 PBS) modeled the intracellular pH ("set-point" pHi 7.35) of intestinal absorptive cells [58]. 
Since the absorption of ciprofloxacin seems to be mainly mediated not by active but by passive diffusion [54], a synthetic membrane was used to separate the two phases.

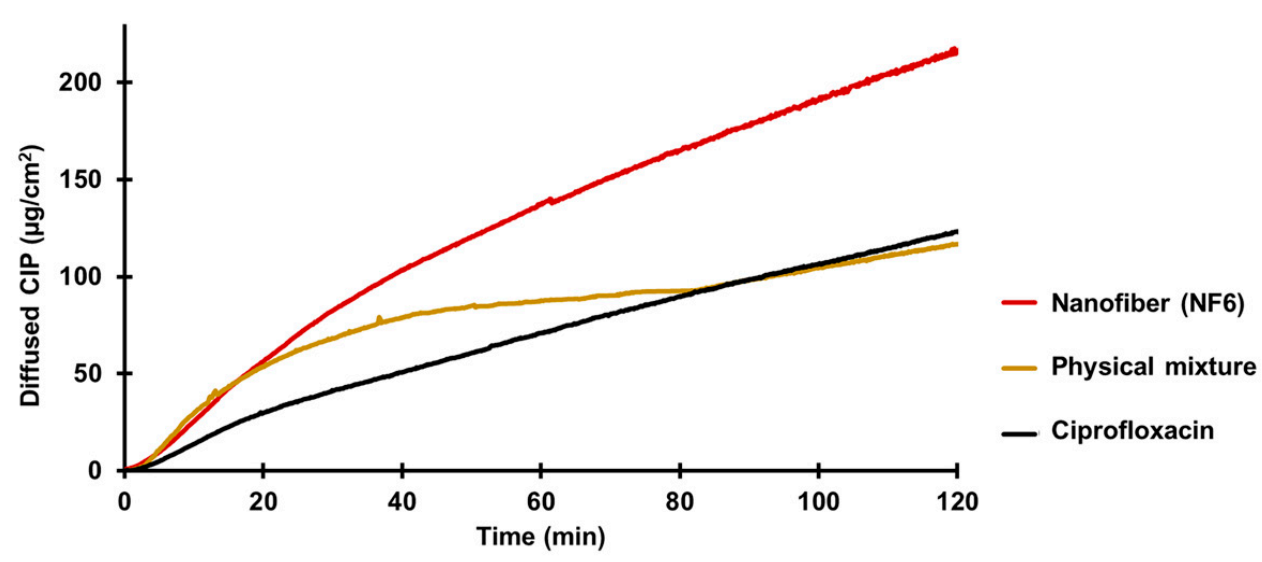

Figure 6. In vitro diffusion of ciprofloxacin (CIP) from the NF6 nanofibrous sample, physical mixture, and CIP powder (SD $\pm 2 \%)$.

According to the results, the diffusion of the CIP was remarkably higher from the nanofibrous sample $\left(215 \mu \mathrm{g} / \mathrm{cm}^{2}\right)$ than the raw CIP $\left(122 \mu \mathrm{g} / \mathrm{cm}^{2}\right)$ or the physical mixture $\left(118 \mu \mathrm{g} / \mathrm{cm}^{2}\right)$. Figure 6 shows the diffusion profiles of CIP from the samples. The diffused CIP over time curve of the physical mixture interestingly runs with the curve of the nanofibrous sample for the first $20 \mathrm{~min}$, but after that it becomes flatter as the CIP diffusion slows down. Finally, at the time range between 80 and $120 \mathrm{~min}$, it overlaps with the curve of the pure CIP powder. This fascinating behavior could be caused by the presence of PVP. As written previously, PVP is a wetting agent that could increase the solubility of a drug. More solute CIP means a higher concentration gradient, which results in faster diffusion. However, the effect of this increase has a limit, and beyond that, the solution and diffusion of CIP slow down.

The calculated flux $(J)$ and permeability coefficient $\left(K_{p}\right)$ values are shown in Table 7 . The diffused CIP amount was 1.7 times higher from the NF6 sample than from the nonfibrous samples. The presence of the PVP did not affect the diffusion since the results of the physical mixture were similar to the CIP powders. Moreover, the permeability coefficient was increased 1.9 times by the nanofiber formulation.

Table 7. Calculated flux $(J)$ and permeability coefficient $\left(K_{p}\right)$ values.

\begin{tabular}{ccc}
\hline Sample & $J\left(\mu \mathrm{g} /\left(\mathrm{cm}^{2} \mathbf{h}\right)\right)$ & $K_{p}(\mathrm{~cm} / \mathbf{h})$ \\
\hline CIP & 60.94 & 0.112 \\
Physical mixture & 58.80 & 0.105 \\
Nanofiber (NF6) & 107.71 & 0.217 \\
\hline
\end{tabular}

\section{Conclusions}

Since CIP is a BSC Class IV drug, various pharmaceutical technological approaches are desirable for improving its bioavailability through the improvement in solubility, dissolution, and permeability. One such approach is the formulation of nanofibers via electrospinning, which is a simple and cost-effective production technique. Electrospun nanofibers, besides solid nanoparticles, are considered as amorphous solid dispersions and promising nanocarriers. Nanofibers are favorable drug carriers because of their high specific surface area, the wide variety of polymers and APIs that are spinnable, the ease of material combination, and the capability for mass production.

In the present study, CIP-loaded nanofibers were successfully fabricated by electrospinning. With the optimized process parameters, the nanofibers had a small, uniform fiber 
diameter with smooth surface morphology. The flow rates used in PVP-based nanofiber fabrication were compared. It was found that a higher flow rate produced thicker fibers, but in the case of too high a flow rate, the fibers were merged because the solvent evaporation was incomplete. According to the results of the XRPD and the DSC measurements, the CIP lost its crystallinity during the electrospinning procedure, and an amorphous form was produced. This form of the drug, along with the increased surface area, is the reason for the significantly higher solubility and in vitro dissolution rate in $\mathrm{pH}$ 7.4 PBS achieved with the nanofibrous samples. In the single medium release study ( $\mathrm{pH} 7.4 \mathrm{PBS}$ ), the nanofibrous formulation demonstrated fast dissolution, and the release kinetics followed the Korsmeyer-Peppas model. In contrast, the raw CIP showed incomplete dissolution due to its poor solubility at this $\mathrm{pH}$ level. To mimic more precisely the in vivo conditions, a twostage biorelevant release study was executed. Since the CIP is more soluble at low pH levels, a supersaturated solution was formed with FaSSGF medium. Then, with the change of the medium to FaSSIF, the solubility of the drug changed, and precipitation occurred. The precipitation could be prevented by nanofibers, since the PVP formed a viscous matrix around the CIP and released it with the dissolution kinetics described the best by Hixson-Crowell model and zero order kinetics. This study predicts a controlled release in the stomach for other API-loaded PVP-based nanofibers that might be useful in the development of local drug delivery systems. Moreover, incorporation of CIP into nanofibers could provide noticeably higher in vitro diffusion through the membrane. Therefore, our results show that CIP-loaded PVP-nanofibers could be considered as fast-dissolving formulations with improved physicochemical properties that may be suitable for further studies to keep in mind when developing an oral dosage form.

Author Contributions: Conceptualization, L.É.U., P.S.-R., and R.A.; methodology, L.É.U., S.Y.K., N.R., V.K., P.S.-R., and R.A.; validation, V.K. and P.S.-R.; formal analysis and investigation, L.É.U. and R.A.; writing—original draft preparation, L.É.U.; writing—review and editing, S.Y.K., N.R., V.K., P.S.-R., and R.A.; visualization, L.É.U. and N.R.; supervision, N.R., V.K., P.S.-R., and R.A.; funding acquisition, R.A. All authors have read and agreed to the published version of the manuscript.

Funding: The publication was funded by The University of Szeged Open Access Fund (FundRef, Grant No. 5249).

Institutional Review Board Statement: Not applicable.

Informed Consent Statement: Not applicable.

Data Availability Statement: The datasets used and/or analyzed are available from the corresponding author on reasonable request.

Acknowledgments: This project was supported by the Gedeon Richter's Talentum Foundation, Gedeon Richter Plc. In addition, the Ministry of Human Capacities, Hungary grant TKP 2020, and EFOP 3.6.3-VEKOP-16-2017-00009 are acknowledged. The authors would like to thank Areen Alshweiat of University of Szeged for her help in the sample preparation and Gábor Katona of University of Szeged and Gregory Myles of The University of Edinburgh for reviewing the paper.

Conflicts of Interest: The authors declare no conflict of interest.

\section{References}

1. Di, L.; Kerns, E.; Carter, G. Drug-Like Property Concepts in Pharmaceutical Design. Curr. Pharm. Des. 2009, 15, $2184-2194$. [CrossRef]

2. Williams, H.D.; Trevaskis, N.L.; Charman, S.A.; Shanker, R.M.; Charman, W.N.; Pouton, C.W.; Porter, C.J.H. Strategies to Address Low Drug Solubility in Discovery and Development. Pharmacol. Rev. 2013, 65, 315-499. [CrossRef] [PubMed]

3. Loftsson, T.; Brewster, M.E. Pharmaceutical Applications of Cyclodextrins: Basic Science and Product Development: Pharmaceutical Applications of Cyclodextrins. J. Pharm. Pharmacol. 2010, 62, 1607-1621. [CrossRef] [PubMed]

4. Olivera, M.E.; Manzo, R.H.; Junginger, H.E.; Midha, K.K.; Shah, V.P.; Stavchansky, S.; Dressman, J.B.; Barends, D.M. Biowaiver Monographs for Immediate Release Solid Oral Dosage Forms: Ciprofloxacin Hydrochloride. J. Pharm. Sci. 2011, 100, 22-33. [CrossRef]

5. Ross, D.; Riley, C. Aqueous Solubilities of Some Variously Substituted Quinolone Antimicrobials. Int. J. Pharm. 1990, 63, 237-250. [CrossRef] 
6. Caço, A.I.; Varanda, F.; Pratas de Melo, M.J.; Dias, A.M.A.; Dohrn, R.; Marrucho, I.M. Solubility of Antibiotics in Different Solvents. Part II. Non-Hydrochloride Forms of Tetracycline and Ciprofloxacin. Ind. Eng. Chem. Res. 2008, 47, 8083-8089. [CrossRef]

7. Radacsi, N.; Ambrus, R.; Szabó-Révész, P.; van der Heijden, A.; ter Horst, J.H. Atmospheric Pressure Cold Plasma Synthesis of Submicrometer-Sized Pharmaceuticals with Improved Physicochemical Properties. Cryst. Growth Des. 2012, 12, $5090-5095$. [CrossRef]

8. Kariminia, S.; Shamsipur, A.; Shamsipur, M. Analytical Characteristics and Application of Novel Chitosan Coated Magnetic Nanoparticles as an Efficient Drug Delivery System for Ciprofloxacin. Enhanced Drug Release Kinetics by Low-Frequency Ultrasounds. J. Pharm. Biomed. Anal. 2016, 129, 450-457. [CrossRef]

9. Zattoni, A. Flow Field-Flow Fractionation for the Analysis of Nanoparticles Used in Drug Delivery. J. Pharm. Biomed. Anal. 2014, 87, 53-61. [CrossRef] [PubMed]

10. Jermain, S.V.; Brough, C.; Williams, R.O. Amorphous Solid Dispersions and Nanocrystal Technologies for Poorly Water-Soluble Drug Delivery-An Update. Int. J. Pharm. 2018, 535, 379-392. [CrossRef]

11. Ogawa, N.; Hiramatsu, T.; Suzuki, R.; Okamoto, R.; Shibagaki, K.; Fujita, K.; Takahashi, C.; Kawashima, Y.; Yamamoto, H. Improvement in the Water Solubility of Drugs with a Solid Dispersion System by Spray Drying and Hot-Melt Extrusion with Using the Amphiphilic Polyvinyl Caprolactam-Polyvinyl Acetate-Polyethylene Glycol Graft Copolymer and d-Mannitol. Eur. J. Pharm. Sci. 2018, 111, 205-214. [CrossRef] [PubMed]

12. Kumar, R. Nanotechnology Based Approaches to Enhance Aqueous Solubility and Bioavailability of Griseofulvin: A Literature Survey. J. Drug Deliv. Sci. Technol. 2019, 53, 101221. [CrossRef]

13. Murdande, S.B.; Pikal, M.J.; Shanker, R.M.; Bogner, R.H. Solubility Advantage of Amorphous Pharmaceuticals: II. Application of Quantitative Thermodynamic Relationships for Prediction of Solubility Enhancement in Structurally Diverse Insoluble Pharmaceuticals. Pharm. Res. 2010, 27, 2704-2714. [CrossRef] [PubMed]

14. Horter, D.; Dressman, J.B. Influence of Physicochemical Properties on Dissolution of Drugs in the Gastrointestinal Tractq. Adv. Drug Deliv. Rev. 2001, 46, 75-87. [PubMed]

15. Günday, C.; Anand, S.; Gencer, H.B.; Munafò, S.; Moroni, L.; Fusco, A.; Donnarumma, G.; Ricci, C.; Hatir, P.C.; Türeli, N.G.; et al. Ciprofloxacin-Loaded Polymeric Nanoparticles Incorporated Electrospun Fibers for Drug Delivery in Tissue Engineering Applications. Drug Deliv. Transl. Res. 2020, 10, 706-720. [CrossRef] [PubMed]

16. Arafa, M.G.; Mousa, H.A.; Afifi, N.N. Preparation of PLGA-Chitosan Based Nanocarriers for Enhancing Antibacterial Effect of Ciprofloxacin in Root Canal Infection. Drug Deliv. 2020, 27, 26-39. [CrossRef] [PubMed]

17. Benedini, L.; Laiuppa, J.; Santillán, G.; Baldini, M.; Messina, P. Antibacterial Alginate/Nano-Hydroxyapatite Composites for Bone Tissue Engineering: Assessment of Their Bioactivity, Biocompatibility, and Antibacterial Activity. Mater. Sci. Eng. C 2020, 115, 111101. [CrossRef]

18. Mocanu, A.-G.; Belu, I. Formulation and Characterization of Ciprofloxacin Loaded PLGA Microspheres for Applications in Orthopedic Infections. Curr. Health Sci. J. 2017, 43, 306-310. [CrossRef]

19. Lamy, B.; Tewes, F.; Serrano, D.R.; Lamarche, I.; Gobin, P.; Couet, W.; Healy, A.M.; Marchand, S. New Aerosol Formulation to Control Ciprofloxacin Pulmonary Concentration. J. Control. Release 2018, 271, 118-126. [CrossRef]

20. Khatib, I.; Tang, P.; Ruan, J.; Cipolla, D.; Dayton, F.; Blanchard, J.D.; Chan, H.-K. Formation of Ciprofloxacin Nanocrystals within Liposomes by Spray Drying for Controlled Release via Inhalation. Int. J. Pharm. 2020, 578, 119045. [CrossRef]

21. Torge, A. Ciprofloxacin-Loaded Lipid-Core Nanocapsules as Mucus Penetrating Drug Delivery System Intended for the Treatment of Bacterial Infections in Cystic Fibrosis. Int. J. Pharm. 2017, 527, 92-102. [CrossRef]

22. Tran, T.-T.; Vidaillac, C.; Yu, H.; Yong, V.F.L.; Roizman, D.; Chandrasekaran, R.; Lim, A.Y.H.; Low, T.B.; Tan, G.L.; Abisheganaden, J.A.; et al. A New Therapeutic Avenue for Bronchiectasis: Dry Powder Inhaler of Ciprofloxacin Nanoplex Exhibits Superior Ex Vivo Mucus Permeability and Antibacterial Efficacy to Its Native Ciprofloxacin Counterpart. Int. J. Pharm. 2018, 547, 368-376. [CrossRef]

23. Rancan, F.; Contardi, M.; Jurisch, J.; Blume-Peytavi, U.; Vogt, A.; Bayer, I.S.; Schaudinn, C. Schaudinn Evaluation of Drug Delivery and Efficacy of Ciprofloxacin-Loaded Povidone Foils and Nanofiber Mats in a Wound-Infection Model Based on Ex Vivo Human Skin. Pharmaceutics 2019, 11, 527. [CrossRef]

24. Yang, S.; Zhang, X.; Zhang, D. Electrospun Chitosan/Poly (Vinyl Alcohol)/Graphene Oxide Nanofibrous Membrane with Ciprofloxacin Antibiotic Drug for Potential Wound Dressing Application. Int. J. Mol. Sci. 2019, 20, 4395. [CrossRef] [PubMed]

25. Paaver, U.; Heinämäki, J.; Laidmäe, I.; Lust, A.; Kozlova, J.; Sillaste, E.; Kirsimäe, K.; Veski, P.; Kogermann, K. Electrospun Nanofibers as a Potential Controlled-Release Solid Dispersion System for Poorly Water-Soluble Drugs. Int. J. Pharm. 2015, 479, 252-260. [CrossRef] [PubMed]

26. Sipos, E.; Kósa, N.; Kazsoki, A.; Szabó, Z.-I.; Zelkó, R. Formulation and Characterization of Aceclofenac-Loaded Nanofiber Based Orally Dissolving Webs. Pharmaceutics 2019, 11, 417. [CrossRef] [PubMed]

27. Villarreal-Gómez, L.J.; Cornejo-Bravo, J.M.; Vera-Graziano, R.; Grande, D. Electrospinning as a Powerful Technique for Biomedical Applications: A Critically Selected Survey. J. Biomater. Sci. Polym. Ed. 2016, 27, 157-176. [CrossRef] [PubMed]

28. Ambekar, R.S.; Kandasubramanian, B. Advancements in Nanofibers for Wound Dressing: A Review. Eur. Polym. J. 2019, 117, 304-336. [CrossRef]

29. Barhoum, A.; Pal, K.; Rahier, H.; Uludag, H.; Kim, I.S.; Bechelany, M. Nanofibers as New-Generation Materials: From Spinning and Nano-Spinning Fabrication Techniques to Emerging Applications. Appl. Mater. Today 2019, 17, 1-35. [CrossRef] 
30. Khodadadi, M.; Alijani, S.; Montazeri, M.; Esmaeilizadeh, N.; Sadeghi-Soureh, S.; Pilehvar-Soltanahmadi, Y. Recent Advances in Electrospun Nanofiber -mediated Drug Delivery Strategies for Localized Cancer Chemotherapy. J. Biomed. Mater. Res. A 2020, 108, 1444-1458. [CrossRef]

31. Udomluck, N.; Koh, W.-G.; Lim, D.-J.; Park, H. Recent Developments in Nanofiber Fabrication and Modification for Bone Tissue Engineering. Int. J. Mol. Sci. 2019, 21, 99. [CrossRef]

32. Park, S.; Park, K.; Yoon, H.; Son, J.; Min, T.; Kim, G. Apparatus for Preparing Electrospun Nanofibers: Designing an Electrospinning Process for Nanofiber Fabrication. Polym. Int. 2007, 56, 1361-1366. [CrossRef]

33. Motamedi, A.S.; Mirzadeh, H.; Hajiesmaeilbaigi, F.; Bagheri-Khoulenjani, S.; Shokrgozar, M. Effect of Electrospinning Parameters on Morphological Properties of PVDF Nanofibrous Scaffolds. Prog. Biomater. 2017, 6, 113-123. [CrossRef]

34. Pelipenko, J.; Kristl, J.; Janković, B.; Baumgartner, S.; Kocbek, P. The Impact of Relative Humidity during Electrospinning on the Morphology and Mechanical Properties of Nanofibers. Int. J. Pharm. 2013, 456, 125-134. [CrossRef] [PubMed]

35. Sun, Y.; Zhu, L.; Wu, T.; Cai, T.; Gunn, E.M.; Yu, L. Stability of Amorphous Pharmaceutical Solids: Crystal Growth Mechanisms and Effect of Polymer Additives. AAPS J. 2012, 14, 380-388. [CrossRef]

36. Yu, D.-G.; Zhang, X.-F.; Shen, X.-X.; Brandford-White, C.; Zhu, L.-M. Ultrafine Ibuprofen-Loaded Polyvinylpyrrolidone Fiber Mats Using Electrospinning: Ultrafine Ibuprofen-Loaded PVP Fibers. Polym. Int. 2009, 58, 1010-1013. [CrossRef]

37. Suganya, S.; Senthil Ram, T.; Lakshmi, B.S.; Giridev, V.R. Herbal Drug Incorporated Antibacterial Nanofibrous Mat Fabricated by Electrospinning: An Excellent Matrix for Wound Dressings. J. Appl. Polym. Sci. 2011, 121, 2893-2899. [CrossRef]

38. Quan, J.; Yu, Y.; Branford-White, C.; Williams, G.R.; Yu, D.-G.; Nie, W.; Zhu, L.-M. Preparation of Ultrafine Fast-Dissolving Feruloyl-Oleyl-Glycerol-Loaded Polyvinylpyrrolidone Fiber Mats via Electrospinning. Colloids Surf. B Biointerfaces 2011, 88, 304-309. [CrossRef] [PubMed]

39. Dai, X.-Y.; Nie, W.; Wang, Y.-C.; Shen, Y.; Li, Y.; Gan, S.-J. Electrospun Emodin Polyvinylpyrrolidone Blended Nanofibrous Membrane: A Novel Medicated Biomaterial for Drug Delivery and Accelerated Wound Healing. J. Mater. Sci. Mater. Med. 2012, 23, 2709-2716. [CrossRef]

40. Jiang, Y.-N.; Mo, H.-Y.; Yu, D.-G. Electrospun Drug-Loaded Core-Sheath PVP/Zein Nanofibers for Biphasic Drug Release. Int. J. Pharm. 2012, 438, 232-239. [CrossRef]

41. Contardi, M.; Heredia-Guerrero, J.A.; Perotto, G.; Valentini, P.; Pompa, P.P.; Spanò, R.; Goldoni, L.; Bertorelli, R.; Athanassiou, A.; Bayer, I.S. Transparent Ciprofloxacin-Povidone Antibiotic Films and Nanofiber Mats as Potential Skin and Wound Care Dressings. Eur. J. Pharm. Sci. 2017, 104, 133-144. [CrossRef]

42. Radacsi, N.; Campos, F.D.; Chisholm, C.R.I.; Giapis, K.P. Spontaneous Formation of Nanoparticles on Electrospun Nanofibres. Nat. Commun. 2018, 9, 4740. [CrossRef] [PubMed]

43. He, P.; Zhong, Q.; Ge, Y.; Guo, Z.; Tian, J.; Zhou, Y.; Ding, S.; Li, H.; Zhou, C. Dual Drug Loaded Coaxial Electrospun PLGA/PVP Fiber for Guided Tissue Regeneration under Control of Infection. Mater. Sci. Eng. C 2018, 90, 549-556. [CrossRef] [PubMed]

44. Li, H.; Zhang, Z.; Godakanda, V.U.; Chiu, Y.-J.; Angkawinitwong, U.; Patel, K.; Stapleton, P.G.; de Silva, R.M.; de Silva, K.M.N.; Zhu, L.-M.; et al. The Effect of Collection Substrate on Electrospun Ciprofloxacin-Loaded Poly(Vinylpyrrolidone) and Ethyl Cellulose Nanofibers as Potential Wound Dressing Materials. Mater. Sci. Eng. C 2019, 104, 109917. [CrossRef]

45. Franco, P.; De Marco, I. The Use of Poly(N-Vinyl Pyrrolidone) in the Delivery of Drugs: A Review. Polymers 2020, $12,1114$. [CrossRef] [PubMed]

46. Mann, J.; Dressman, J.; Rosenblatt, K.; Ashworth, L.; Muenster, U.; Frank, K.; Hutchins, P.; Williams, J.; Klumpp, L.; Wielockx, K.; et al. Validation of Dissolution Testing with Biorelevant Media: An OrBiTo Study. Mol. Pharm. 2017, 14, 4192-4201. [CrossRef]

47. Sang, Q.; Williams, G.R.; Wu, H.; Liu, K.; Li, H.; Zhu, L.-M. Electrospun Gelatin/Sodium Bicarbonate and Poly(Lactide-Co- Caprolactone)/Sodium Bicarbonate Nanofibers as Drug Delivery Systems. Mater. Sci. Eng. C 2017, 81, 359-365. [CrossRef]

48. Yan, S.; Xiaoqiang, L.; Shuiping, L.; Xiumei, M.; Ramakrishna, S. Controlled Release of Dual Drugs from Emulsion Electrospun Nanofibrous Mats. Colloids Surf. B Biointerfaces 2009, 73, 376-381. [CrossRef]

49. Cleeton, C.; Keirouz, A.; Chen, X.; Radacsi, N. Electrospun Nanofibers for Drug Delivery and Biosensing. ACS Biomater. Sci. Eng. 2019, 5, 4183-4205. [CrossRef]

50. Radacsi, N.; Giapis, K.P.; Ovari, G.; Szabó-Révész, P.; Ambrus, R. Electrospun Nanofiber-Based Niflumic Acid Capsules with Superior Physicochemical Properties. J. Pharm. Biomed. Anal. 2019, 166, 371-378. [CrossRef]

51. Karimi, K.; Pallagi, E.; Szabó-Révész, P.; Csóka, I.; Ambrus, R. Development of a Microparticle-Based Dry Powder Inhalation Formulation of Ciprofloxacin Hydrochloride Applying the Quality by Design Approach. Drug Des. Devel. Ther. 2016, 10, 3331-3343. [CrossRef] [PubMed]

52. Kataria, K.; Gupta, A.; Rath, G.; Mathur, R.B.; Dhakate, S.R. In Vivo Wound Healing Performance of Drug Loaded Electrospun Composite Nanofibers Transdermal Patch. Int. J. Pharm. 2014, 469, 102-110. [CrossRef]

53. Fallingborg, J. Intraluminal PH of the Human Gastrointestinal Tract. Dan. Med. Bull. 1999, 46, 183-196. [PubMed]

54. Hansmann, S.; Miyaji, Y.; Dressman, J. An in Silico Approach to Determine Challenges in the Bioavailability of Ciprofloxacin, a Poorly Soluble Weak Base with Borderline Solubility and Permeability Characteristics. Eur. J. Pharm. Biopharm. 2018, 122, 186-196. [CrossRef] [PubMed]

55. Permanadewi, I.; Kumoro, A.C.; Wardhani, D.H.; Aryanti, N. Modelling of Controlled Drug Release in Gastrointestinal Tract Simulation. J. Phys. Conf. Ser. 2019, 1295, 012063. [CrossRef] 
56. Supramaniam, J.; Adnan, R.; Mohd Kaus, N.H.; Bushra, R. Magnetic Nanocellulose Alginate Hydrogel Beads as Potential Drug Delivery System. Int. J. Biol. Macromol. 2018, 118, 640-648. [CrossRef] [PubMed]

57. Harder, S.; Fuhr, U.; Beermann, D.; Staib, A. Ciprofloxacin Absorption in Different Regions of the Human Gastrointestinal Tract. Investigations with the Hf-Capsule. Br. J. Clin. Pharmacol. 1990, 30, 35-39. [CrossRef] [PubMed]

58. Calonge, M.L.; Ilundáin, A. Na+-H+ Exchange Activity and Cellular PH Regulation in Enterocytes Isolated from Chick Small Intestine. Biochim. Biophys. Acta BBA Biomembr. 1990, 1029, 201-210. [CrossRef] 